\title{
2001 Krizinin Dolarizasyon Boyutunda VAR Analiziyle Değerlendirilmesi
}

Ayşegül AK ${ }^{1}$

Makale Gönderim Tarihi: 27 Temmuz 2021

Makale Kabul Tarihi: 15 Eylül 2021

$\ddot{O} \mathbf{z}$

2020 yılının tüm dünya ülkeleri için bir kriz yılı olarak tanımlanmasıyla literatürdeki kriz konuları tekrar gündeme gelmiş ve geçmiş krizlerle kovid19 virüsünün neden olduğu kriz arasındaki farklılıklar ve benzerlikler artan oranda tartışılmaya başlanmıştır. Tüm krizlerde makroekonomik verilerin hızla bozulmasından hareketle Türkiye' de gerçekleşen 2001 krizine ait değişkenlerin özellikle kredi dolarizasyonuyla ilişkilendirilmesi çalışmanın temel çıkış noktasını oluşturmaktadır. Öncelikle dolarizasyonun ekonomiye yüklediği maliyet olarak krizler tartışılmış ve analiz kısmında da kredi ve mevduat olarak ikiye ayrılıp faiz değişimi, kur değişimi, enflasyon ve Gayri Safi Yurtiçi Hasıla değişimi ile ilişkisi ortaya konmaya çalışılmıştır. Analiz sonuçlarına göre kredi dolarizasyonunu ele alınan değişkenlerin açılama gücü \% 65 gibi sosyal bilimler için yüksek sayılabilecek bir değerde bulunmuştur.

Anahtar kelimeler: Finansal kriz, VAR model, dolarizasyon

JEL Sinıflandirmasi: E44, C01, F31

$1 \quad$ Dr. Öğretim Üyesi, Başkent Üniversitesi, İiBF, İşletme Bölümü, aysegulak@baskent.edu.tr, Orcid id: 0000- 0003-1434-3103 


\title{
Evaluation of 2001 Crisis in Dollarization Dimension with VAR Analysis
}

\begin{abstract}
As a crisis for being used all over the world in 2020, the similarities caused by the covid19 virus with the previous and past crises in the literature began to be increasingly discussed. So, the main starting point of the study is to associate the variables of the 2001 crisis in Turkey, especially with credit dollarization. First of all, the crisis as the cost of dollarization to the economy was discussed and with the analysis part, dollarization divided into two as credit and deposit dollarization and its relationship with interest change, exchange rate change, inflation and Gross Domestic Product change has been tried to be revealed. According to the results of the analysis, $65 \%$ of the explanations of people like dealing with credit dollarization were considered to be of high value for the social sciences.
\end{abstract}

Keywords: Financial crisis, logit model, dollarization

JEL Codes: E44, C01, F31

\section{Giriş}

Finansal krizler dünya tarihinde önemli bir yer tutmaktadır. Bunları başlatan faktörler farklı farklı olsa da küreselleşmenin etkisiyle, krizlerin sonucunun geniş bir alana hatta dünyanın tümüne yayıldığı görülmektedir. Benzer şekilde; 2019 yılı sonunda Çin'in Wuhan eyaletinde ortaya çıkan kovid_19 salgınının pandemiye dönüşmesiyle etkisini yıllar boyu sürdürecek ve reel ekonomiden finansal sisteme her kesimin etkileneceği yaygın bir kriz dönemi başlamış oldu. Çin'in dünyanın en önemli tedarikçisi olması nedeniyle arz yönlü başlayan kriz, pandeminin yayılmasını engellemeye yönelik sosyal izolasyon tedbirleri sonucu talep yönlü bir krize evrilince 2020 y1lı, tüm dünya ülkeleri için bir kriz yılı olarak tanımlanmıştır. Böylelikle geçmiş kriz dönemleri ve literatürdeki kriz konuları tekrar gündeme gelmiş ve geçmiş krizlerle koronavirüsün neden olduğu kriz arasındaki farkl1lıklar ve benzerlikler artan oranda tartışılmaya başlanmıştır. Özellikle, Türkiye açısından önemli sonuçları olan 2001 krizine dair çalışmalar güncelliğini korumaktadır. Bu çalışmada da 2000, 2001 ve 2008 yıllarında yaşanmış kriz dönemlerinde etkili olduğu düşünülen makroekonomik değişkenlerin finansal kriz olasılığını tespit etmedeki rolü araştırılmış böylelikle kriz dönemlerinde üzerinde önemle durulması gereken değişkenlerin tespiti amaçlanmıştır. 


\section{Literatür}

Kriz tanımı, birçok alanda kullanılmakla birlikte, herhangi bir alanda kullanılırsa kullanılsın ele alınan bir değişkenin ortalama değerinin üzerinde ve kabul edilebilir sınırların ötesinde bir değişim göstermesi durumudur. Dünyanın pek çok ekonomisinde farklı finansal krizler meydana gelmiştir. 1929 Büyük Buhranı, 1994 Meksika krizi, 1997 Asya krizi, 1998 Rusya krizi ve 2008 Amerika Birleşik Devletleri mortgage piyasasında ortaya çıkan krizler tüm dünya ülkelerini etkilemiştir.

Literatürde finansal kriz olarak adlandırılan sürecin bulaşma etkisiyle diğer ülkelere de yayılması son zamanlarda üzerinde en fazla tartışılan konulardan biri haline gelmiştir. Arteta (2003)'a göre kriz, ekonomide aniden ve beklenmedik bir şekilde ortaya çıkan olayların makro açıdan ülke ekonomisini, mikro açıdan ise firmaları ciddi anlamda sarsacak sonuçlar ortaya çıkarmasıdır. Rosier (1994)'e göre kriz, ulusal ekonomide dışsal nedenlerle patlak veren ve etkileri içsel nedenlerle yayılan bir taşkınlıktır.

Uluslararas1 Para Fonu'nun 1998 yılında yayınladığ raporunda finans krizini döviz krizi ve bankacılık krizi olarak farklı başlıklar altında toplamıştır. Buna göre, döviz krizi, paraya yapılan bir spekülatif atağın devalüasyona veya merkez bankasının parayı savunmak için büyük rezervler harcadığında ya da faiz oranlarını büyük miktarda yükselttiğinde gerçekleşmekte, bankac1lık krizi ise, banka paniğinde ya da paniğin olma ihtimalinde bankaların yükümlülüklerini çevirememesi sonucu devletin müdahaleye mecbur kalmasında oluşmaktadır (IMF, 1998) .

Krizlerin dünya ekonomik tarihinde oldukça önem arz ettiği görülmektedir. Finansal krizler, döviz ya da diğer adıyla para krizleri, bankacılık krizleri ve ikiz krizler olarak ayrılmaktadır. Para krizi olarak tanımlandığı da görülen döviz krizleri, teorik ve görgül çalışmaların pek çoğuna araştırma konusu olmuş tartış1lmaya devam edilen konulardan biridir. Krugman (1997)'in belirttiği gibi; hala çözülememiş pek çok nokta vardır ve her bir yeni kriz ile yeni yap bozlar ortaya çıkmaktadır.

Döviz krizlerini açıklamaya yönelik modeller geliştirilmiştir. Bu modeller birinci, ikinci ve üçüncü nesil olarak gruplanmaktadır. Krizlerin çıkma ve üretilen modellerin zamanlarına bakıldığında literatürde oluşan modellerin ihtiyaçlardan çıktığı görülmektedir. Birinci nesil modeller aynı zamanda kanonik modeller olarak da anılmaktadır. Sürdürülmesi mümkün olmayan mali politikaların sabit döviz kuru sisteminin çökmesine neden olduklarına vurgu yapan modellerdir. Bu modellerin dayanağını Henderson ve Salant (1978), Flood ve Garber (1984)' in altın piyasasında spekülatif saldırıları konu aldıkları çalışmalar oluşturmaktadır. 
İlk kriz modellerinde kriz, sabit kur uygulayan ülkelerde ülke parasına karşı spekülatif saldırı olmasıyla ortaya çıkan yüksek dereceli devalüasyon ile ortaya çıkmaktadır. Yeni gelişmelere bakıldığında serbest dalgalı kur rejiminde, ülke parasının büyük ölçüde devalüasyona uğramasıyla makroekonomik dengelerin bozulması sonucu başlayan krizler görülmektedir. Yeni krizlerde, sabit kur rejimini sürdürebilmek için gerekli olan merkez bankasının döviz rezervlerinin erimesi sonucu sabit kurun sürdürülemeyip dalgalanmaya bırakılmasının yerini, paranın fazla dalgalanmasını önleyici politikaların uygulanamaması almaktadır ki bu da dolaylı olarak rezervler ile ilişkilidir.

Birinci nesil kriz modellerinde finansal krizlerin ekonomi politikalarındaki temel dengesizlikler ve döviz kurunu sabit tutma arasındaki tutarsızlıktan kaynaklandığı savunulmaktadır. Sabit kur rejiminde hükümetin bütçe açıklarının finansmanı üzerindeki kontrolü ortadan kalkmaktadır. Hükümet para arzını özel sektörün elinde tutmak istediği miktarın üzerine çıkarttığında, ülkedeki özel yatırımcılar yabancı paraya yönelerek döviz kuru üzerindeki etki ile merkez bankası rezervlerinin ciddi oranda azalmasina neden olmaktadirlar (Krugman, 1979). Birinci nesil modeller (kanonikal) Krugman (1979) ile başlarlar. Varsayımsal durum sabit döviz kurunun uygulandığı durumdur. Krizler, sabit kuru sürdürmeye olanak tanımayan politikaların ürünüdür. Uluslararası rezervleri yeteri kadar olmayan ülkede sabit kuru sürdürebilecek imkan kalmaz ve ulusal para dalgalanmaya bırakılır. Paranın dalgalanmasıyla yeni bir denge kuru oluşur ve ileriye dönük beklentilerini sabit kura göre ayarlayanların riskleri artar. Krugman'ın kriz modelinde uluslararası rezervlerin, döviz kuru ve ödemeler dengesi gibi temel ekonomik parametreler üzerine kurulu olduğu, spekülatif saldırıları önleyecek kadar rezerv yok ise sabit kuru sürdürmenin olanaksızlığı anlaşılmaktadır. Ayrıca, bu modele göre, kurun dalgalanmas1 sonras1 yeniden sabitlenmesi planlaniyor ise uluslararası rezervler mümkün olabildiğince artırılmalıdır.

1990'ların başında Avrupa Para Sistemi kriz ortaya çıkınca ilk nesil kriz modellerinin krizlere ilişkin pek çok noktayı kaçırdığı ve yetersiz oldukları ortaya çıkmış ve Obstfeld (1994) ile ikinci nesil modeller gelişmiştir. Birinci nesil modellerden farklı olarak ikinci nesil modeller, rezerv düzeyinin spekülatif ataklar üzerindeki etkisinin az olduğu, kendi kendini besleyen spekülatif ataklar üzerine kuruludur. Burnside, Eichenbaum ve Rebello (2001)'ya göre; ilk nesil modellerde sabit kur uygulamak için hükümet dışsal belirlenmiş bir kurala bağlı kalmakta iken, ikinci nesil modellerde hükümet açık belirlenmiş bir amaç fonksiyonunu maksimize etmekte ve bu maksimizasyon problemi hükümete ne zaman sabit kur uygulaması gerektiğini sunmaktadır. İkinci nesil modellerde, hükümetin sabit kuru sürdürmek ya da vazgeçmek gibi iki seçeneği vardır. Karar alıcılar ise beklentilerinin şekillendirmesiyle hareket ederler. 
Hükümet söz verdiği kredibiliteyi korumak ve makro politikaları daha rahat uygulayabilmek adına sabit kur sistemini korumayı tercih eder. Ancak kuru korumak zor olduğundan zamanla karar alıcıların bekleyişleri sabit kurun sürdürülemeyeceği yönünde değişir. Yeni kararlarını bu algıya göre ayarlayarak alanlar zaten sabit kurun sürdürülmesini imkansız hale getirmiş olmaktadırlar.

Bleaney, Bougheas ve Skamnelos (2008), döviz krizleriyle ilgili ikinci nesil modele ait çalışmalarında bankacılık sisteminden kaçışların döviz krizine yol açacağını (veya tam tersi) belirtmişlerdir. Sabit kur rejiminde, banka varlıklarının durumu, ve/veya kur rejimiyle ilgili bilgiler ikiz krizlere yol açabilmektedir. İkiz krizlerin oluşup oluşmaması, diğer mevduat sahiplerinin kararlarına ilişkin beklentilere göre ortaya çıkmaktadır. Diğer mudilerin de paralarını çekecekleri beklentileri hakim ise banka borçlarını ödeyememe riskine girmeden parasını çekmek isteyenler banka paniklerini başlatacaklardır. Sabit kur rejimi altında, kura dair olumlu beklentiye sahip olanlar yerli para cinsinden varlıklara, görece kötümser beklentiye sahip olanlar da yabancı para varlıklara yönelecekler, bu durumda döviz piyasasında kötü bir sinyal oluşursa, develüasyona karşı etkin bir şekilde sigortalandıklarını düşünerek bankadan paralarını çekmeyi düşünmeyeceklerdir. Ancak yerli para mevduat sahipleri, paralarını bankada tutmaktan daha çok beklenen getiriyi paralarını yabancı paraya çevirdiklerinde elde edecekler ise mevduatlarını çekmek için halen bir nedenleri olacaktır. Bu durumda bankalar, yerli para mevduatları yabancı para mevduatlara çevirmeyi teklif etseler de kurun ne kabul edileceği bir sorundur. Her durumda mevduat sahipleri ilk başta yabancı para mevduat alanlardan daha az kazanacaklardır. Yerli para mevduat sahipleri tercihlerini, bankadan paralarını alıp piyasada yabancı paraya çevirmek ya da bankanın kendilerine sunduğu o anki kurdan yabancı para mevduata çevirmek arasında yapacaklardır.

Üçüncü Nesil Modeller, devalüasyonlara bağlı bilanço etkilerini dikkate alan, finansal sektöre ilişkin sıkıntıları döviz krizleriyle ilişkilendiren modellerdir.

"Krizlerin bulaşma etkisi üçüncü nesil modeller ile önem kazanmıştır. Bulaşma, farklı ülkelerdeki finansal değişkenlerin yüksek korelasyon derecesinde birlikte hareket etmeleri durumudur. Krizlerin pek çok ülkeyi etkilemesinin temel nedeni bulaşma etkisidir. Krizlerin bulaşma etkisiyle yayılmasının nedenleri üç başlık altında incelenebilmektedir. Krizler ortak bir nedenden kaynaklanıyor olabilirler. Muson etkisi de denilen durum, gelişmiş ülke ekonomilerindeki kaymaların gelişmekte olan ülkelerdeki krizleri tetiklemesidir. 1980'lerde ABD faiz oranlarının artması Latin Amerika'da borç krizinde etkendir. Dışarıdaki gelişmeler krizlere katkıda bulunurken, bir ülkeyi krize karş1 kırılgan yapan tüketim için aşırı borçlanma, kırılgan bir finans sektörü, esnek olmayan döviz kuru sistemi gibi yurtiçi ekonomik koşullar ve politika- 
lardır. Krizlerin zaman içerisinde neden bir araya toplandığını açıklayan ikinci neden; bir ülkedeki krizin, ticaret veya sermaye piyasası bağlarıyla veya kredi veren kuruluşların portföylerinin birbirlerine bağlı olmasıyla (örneğin likidite sıkışıklı̆g 1 sonucu finansal aracıların diğer piyasalardaki likitleri aktif hale getirmesi) bir başka ekonomideki temel göstergeleri etkilemesidir. Karş1lıklı bağımlılıktan kaynaklanan bu tür dışsallıkların Asya krizinin yayılmasında büyük etkisi olmuştur. Üçüncü neden; kredi veren kuruluşların, diğer ülkelerin temel göstergeleri değişmemiş olsa da bu kuruluşların portföy risklerini düşürmek için temel göstergeleri yeniden yorumlamasıdır. Bu etki, bulaşma diye anılmaktadır." (IMF, 1998).

"Tarih, döviz krizlerinin bulaşma etkisine sahip olduğunu, sadece komşu ülkeleri değil, coğrafi açıdan çok uzak olsalar dahi krizlerin hızla yayılabildiğini göstermiştir. Bu durumun ilk akla gelen nedeni, ülkelerin temel zayıflıklarının aynı olduğu ya da aynı şok dalgası ile vurulmaları olabilir. Bulaşma üzerine bir başka varsayım ise bir ülkenin kriz yaşayarak parasını devalüe etmesinin ortak ve rakip ülkeleri de aynı şekilde etkileyeceğidir" (Y1lmazkuday, 2008).

Feldstein (2002)'e göre finans krizi riskini düşürmenin temel yolları; yabancı para cinsinden büyük borçlardan özellikle de özel sektör borcundan kaçınmak, paranın dalgalanmasını sağlayarak aşırı değerlenmesinin önüne geçmek, döviz rezervlerini önemli ölçülerde tutmak, kısa vadeli döviz yükümlülüklerini düşük tutmak ve sağlam bir bankacılık sistemi sürdürmektir. Görüldüğü gibi kur politikalarının önemine değinen, temelinde kurun istikrarı yatan kriz önleyici maddeler, kur politikasının önemini göstermektedir.

Kamu bankalarının kaynaklarının kamu yararına kullandırılması da sistemin krize sürüklenmesine yol açabilmektedir. Bankacılık krizleri ile döviz krizlerinin peş peşe gerçekleşmeleri sistemin bir ayağındaki bozulmanın diğerlerine de çok hızlı sıçradığının bir göstergesidir. Döviz ve bankacılık krizlerinin birbiriyle bağlantılı olmanın ötesinde beraber ortaya çıktılarını açıklayan kriz tanımı ikiz krizlerdir. Bankacılık krizleri, sistemin zayıf yönleri ile makroekonomik değişkenlerdeki dengesizliklerin birleşmesi sonucu oluşmaktadır. Aktif-pasif vade uyumsuzluğu, kur uyumsuzluğu, aktif kalitesindeki kötüleşme, operasyonel verimsizlik ile faiz oranları, döviz kuru gibi önemli değişkenlerdeki istikrarsızlık bankaları sıkıntıya düşüren etken faktörlerdir. Kişilerin beklentilerini değiştirerek mevduatlarını çekmek istemeleri de bankacılık krizini başlatan unsur olabilmektedir.

\section{Veri ve Metodoloji}

Verilerin derlenmesinde, Türkiye Cumhuriyet Merkez Bankası'nın web sitesinde yer alan elektronik veri dağıtım sisteminden (EVDS) ve Uluslararası 
Para Fonu'nun International Financial Statistic (IFS) serilerinden yararlanılmıştır. Seriler 1996Q2-2008Q3 arasındaki dönemi kapsamaktadır.

Bu bölümün amac1, kredi dolarizasyonunun ekonomiye yüklediği riskler nedeniyle dört temel makroekonomik değişken ile mevduat dolarizasyonu arasındaki etkileşimin araştırılmasıdır. Belirlenen makroekonomik değişkenler, enflasyon, faiz değişimi, kur değişimi ve Gayri Safi Yurtiçi Hasıla büyümesidir.

Verilerin derlenmesinde, Türkiye Cumhuriyeti Merkez Bankası'nın web sitesinde yer alan elektronik veri dağıtım sisteminden (EVDS) ve Uluslararas1 Para Fonu'nun International Financial Statistic (IFS) serilerinden yararlanılmıştır. Seriler 1996Q2-2008Q3 arasını kapsamaktadır.

Çalışmada kullanılan vektör otoregresyon diğer adıyla vektör ardışık bağlanım modeli (VAR) modeli, Christopher Sims tarafından geliştirilen, içsel ve dışsal değişkenler arasında önsel bir ayrım yapmayan regresyon yöntemidir. Bir değişken takımı arasında eşanlılık var ise hepsi eşit biçimde ele alınmalıdır. Ardışık bağlanım terimi, bağımlı değişkenin gecikmeli değerinin denklemin sağında yer almasından, vektör terimi de iki ya da daha çok değişkenden oluşan bir vektörün ele alınmasından gelmektedir (Gujarati, 2001).

"Bir VAR modelinde sistemde yer alan tüm değişkenler içseldir ve her biri kendi gecikmeli değerleri ile sistemde yer alan tüm değişkenlerin gecikmeli değerlerinin doğrusal bir fonksiyonu olarak tanımlanır. Burada gecikme sayısı tespit edilir. Tüm değişkenlerin tek bir vektörde toplanması durumunda, bu vektör otoregresyon modeli olarak görülebilir ki bu vektör kendi gecikmeli değerleri artı hata vektörünün doğrusal bir fonksiyonu olarak gösterilir. Tahmin her değişken için ayrı ayrı ve diğer değişkenlerin gecikmeli değerlerinden oluşan regresyon modeli ile yapılır." (Kennedy, 2006).

$\mathrm{Bu}$ açıklamalar 1şığında araştırılan regresyon modeli şu şekilde yazılabilir:

$$
\mathrm{Y}_{\mathrm{t}}=\mathrm{a}+\mathrm{b} 1 \mathrm{Y}_{\mathrm{t}-1}+\mathrm{b}_{2} \mathrm{Y}_{\mathrm{t}-2}+\ldots+\mathrm{b}_{\mathrm{n}} \mathrm{Y}_{\mathrm{t}-\mathrm{n}}+\mathrm{c}_{\mathrm{k}} \mathrm{X}_{\mathrm{k}}+\mathrm{e}_{\mathrm{t}}
$$

$\mathrm{Y}$; kredi dolarizasyonu, $\mathrm{X}_{\mathrm{k}}$; mevduat dolarizasyonu, enflasyon, faiz değişimi, kur değişimi, Gayri Safi Yurtiçi Hasıla büyümesi, n; gecikme uzunluğu, e; hata terimidir.

Kredi dolarizasyonu, mevduat bankaları ile kalkınma yatırım bankalarının kullandırdıkları yabancı para kredilerin bankacılık sistemi kredi hacmi içindeki oranıdır. 
Mevduat dolarizasyonu, yerleşiklerin yabancı para mevduatlarının toplam mevduatlara oranıdır.

Enflasyon, tüketici fiyat endeksi değişimidir.

Faiz değişimi, IFS'in sunduğu, Türkiye interbank para piyasası faiz oranındaki değişim alınmıştır.

Kur değişimi, TCMB dolar alış kurundaki değişimdir.

Gayri Safi Yurtiçi Hasıla büyümesi, üçer aylık GSYİH artışlarıdır. Mevsimsellik tespit edildiği için öncelikle Tramo/Seats yöntemi kullanılarak mevsimsellikten arındırılan seri kullanılmıştır.

\section{Grafik1. Değişkenlerin Zamansal Değişimi}
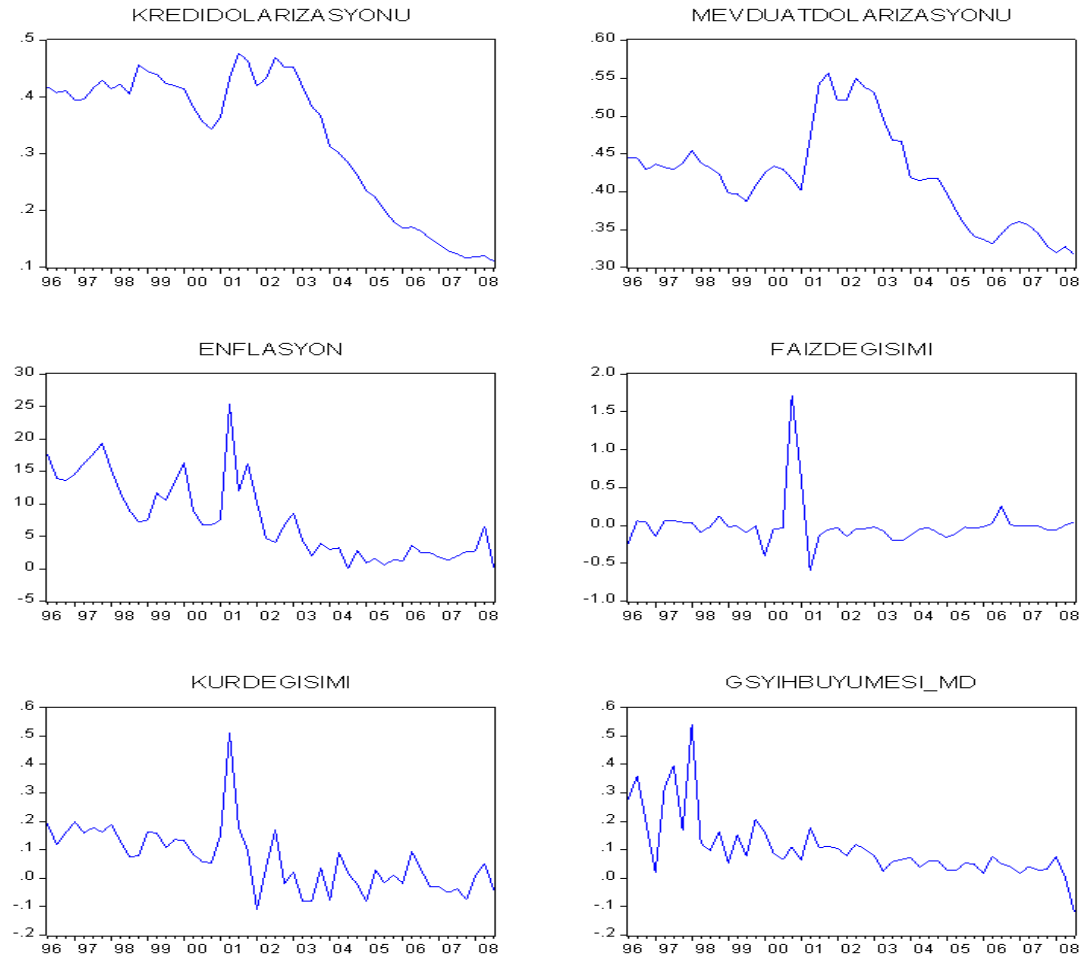

Analize başlamadan önce kullanılacak gecikme uzunluğu ve veri serilerinin durağanlık testlerinin yapılarak birim kök olup olmadığının araştırılması gerekmektedir. Tablo1'de gecikme kriterlerine ilişkin analizin sonuçları verilmiştir. 
Tablo 1. Gecikme Uzunluğunun Belirlenmesi

\begin{tabular}{ccccccc}
\hline Gecikme & LogL & LR & FPE & AIC & SC & HQ \\
\hline 0 & 199.7644 & NA & $7.33 \mathrm{e}-12$ & -8.611752 & $-8.370863^{*}$ & -8.521951 \\
1 & 254.2531 & 92.02528 & $3.27 \mathrm{e}-12$ & -9.433469 & -7.747251 & -8.804864 \\
2 & 294.8153 & 57.68849 & $2.91 \mathrm{e}-12$ & -9.636235 & -6.504687 & -8.468825 \\
3 & 341.2797 & 53.69217 & $2.32 \mathrm{e}-12$ & -10.10132 & -5.524440 & -8.395104 \\
4 & 410.8922 & $61.87779^{*}$ & $8.68 \mathrm{e}-13^{*}$ & $-11.59521^{*}$ & -5.572999 & $-9.350189^{*}$ \\
\hline
\end{tabular}

LR: sequential modified LR test statistic

FPE: Final prediction error

AIC: Akaike information criterion

SC: Schwarz information criterion

HQ: Hannan-Quinn information criterion

*Yukarıda açılımları verilen testlerin belirtmiş olduğu uygun gecikme uzunluğunu belirtmektedir.

Schwartz bilgi kriterine göre hiç gecikme kullanılmaması gerekmekle birlikte, diğer kriterlerin tamamı 4 dönemi işaret ettiği için gecikme uzunluğu 4 olarak belirlenmiştir.

Regresyon sonuçlarının sahte sonuçlar vermesi zaman serilerinde olası durumlardan biridir. Bunu engellemek için analize tabi tutulan serilerin birim kök içerip içermediklerinin araştırılması gereklidir. Serinin birim kök içermesi durağan olmadığı anlamına gelmektedir. En yaygın kullanılan Augmented Dickey-Fuller Testinde boş hipotez, serinin birim köke sahip olmasıdır. Serinin birim kökten kurtulması amacıyla farkı alınarak durağan serinin analize katılması sağlanmalıdır. Bu amaçla Tablo2'de her bir değişken serisinin birim köke sahip olmayan düzeyinin bulunması amaciyla yapılan ADF test sonuçları sunulmuştur.

'Durağanlık zaman serisinin birim kökü olup olmadığına bakılarak anlaşılır. Dickey Fuller ya da Genişletilmiş Dickey Fuller sınamaları bu amaçla kullanılır. Bir seriyi durağan yapmak için d kez farkı alınır. Zaman serisi I(d) ise d kez farkı alınınca I(0) olur. I(0) seri, birim kökü olmayan serdir.'(Gujarati, 2001) 
Tablo 2. Serilerin Durağanlığının Belirlenmesi

\begin{tabular}{lccl}
\hline Değişken & Durum & P değerleri & Değerlendirme \\
\hline Kredi dolarizasyonu & düzey & 0.9459 & Durağan değil \\
Mevduat dolarizasyonu & 1. fark & 0.0002 & Durağan \\
& düzey & 0.8265 & Durağan değil \\
Kur değişimi & $1 . f a r k$ & 0.0002 & Durağan \\
Enflasyon & düzey & 0.0054 & Durağan \\
& düzey & 0.5890 & Durağan değil \\
Faiz değişimi & 1.fark & 0.0000 & Durağan \\
GSYïH değişimi & düzey & 0.0000 & Durağan \\
\hline
\end{tabular}

P değerlerinin bulunmasında sabit terim varsayımı altında Akaike Bilgi Kriteri kullanılmış, anlamlılık düzeyi 0.05 alınmıştır.

Durağanlık testi, seriler durağan çıkıncaya kadarki düzeyleri için devam ettirilmiş, dolayısıyla düzeyde durağan seri için birinci fark alınmasına gerek duyulmamıştır.

VAR analizi yapılırken değişkenlerin durağan seyrettikleri düzeyler modele katılmış ve sonuçları Tablo 3 'te sunulmuştur.

Tablo 3. VAR Analizi Sonuçları

\begin{tabular}{|l|c|c|c|c|c|c|}
\hline & KREDI DOL. & MEVD.DOL. & ENF. & FAiZ & KUR & GSYIH \\
\hline KREDI DOL.(-1) & 0.766969 & 0.459952 & 103.8259 & -6.144240 & 0.757967 & 1.142568 \\
& $(0.29788)$ & $(0.31340)$ & $(49.3895)$ & $(7.03505)$ & $(1.30350)$ & $(1.85461)$ \\
& {$[2.57474]$} & {$[1.46760]$} & {$[2.10218]$} & {$[-0.87338]$} & {$[0.58149]$} & {$[0.61607]$} \\
& & & & & & \\
KREDI DOL.(-2) & -0.283874 & -0.244800 & -35.12691 & -2.023635 & -1.080892 & -0.471424 \\
& $(0.20655)$ & $(0.21731)$ & $(34.2463)$ & $(4.87805)$ & $(0.90383)$ & $(1.28597)$ \\
& {$[-1.37436]$} & {$[-1.12649]$} & {$[-1.02571]$} & {$[-0.41485]$} & {$[-1.19590]$} & {$[-0.36659]$} \\
& & & & & & \\
KREDI DOL(-3) & -0.537400 & -0.269185 & -8.922778 & -4.116981 & -0.340990 & -0.801487 \\
& $(0.17460)$ & $(0.18369)$ & $(28.9485)$ & $(4.12343)$ & $(0.76401)$ & $(1.08704)$ \\
& {$[-3.07795]$} & {$[-1.46539]$} & {$[-0.30823]$} & {$[-0.99844]$} & {$[-0.44631]$} & {$[-0.73731]$} \\
& & & & & & \\
KREDI DOL (-4) & 0.454526 & 0.108624 & 25.19243 & -2.175055 & -1.076159 & -1.553552 \\
& $(0.20820)$ & $(0.21905)$ & $(34.5204)$ & $(4.91709)$ & $(0.91107)$ & $(1.29627)$ \\
& {$[2.18309]$} & {$[0.49588]$} & {$[0.72978]$} & {$[-0.44235]$} & {$[-1.18121]$} & {$[-1.19848]$} \\
& & & & & & \\
MEVDUAT DOL(-1) & -0.543622 & -0.298694 & -104.0929 & 1.056316 & -2.537269 & -2.783775 \\
& $(0.28958)$ & $(0.30467)$ & $(48.0137)$ & $(6.83908)$ & $(1.26719)$ & $(1.80295)$ \\
& {$[-1.87725]$} & {$[-0.98037]$} & {$[-2.16798]$} & {$[0.15445]$} & {$[-2.00229]$} & {$[-1.54401]$} \\
& & & & & & \\
MEVDUAT DOL.(-2) & -0.122725 & -0.037808 & -1.334999 & 1.773823 & -0.294827 & 0.132744 \\
\hline
\end{tabular}




\begin{tabular}{|c|c|c|c|c|c|c|}
\hline & $(0.26561)$ & $(0.27945)$ & $(44.0380)$ & $(6.27278)$ & $(1.16226)$ & $(1.65366)$ \\
\hline & {$[-0.46206]$} & {$[-0.13529]$} & {$[-0.03031]$} & {$[0.28278]$} & {$[-0.25367]$} & [ 0.08027$]$ \\
\hline \multirow[t]{3}{*}{ MEVDUAT DOL.(-3) } & 0.730220 & 0.190792 & -32.27861 & 4.124050 & -0.827188 & -2.758222 \\
\hline & $(0.24984)$ & $(0.26285)$ & $(41.4232)$ & $(5.90032)$ & $(1.09325)$ & (1.55547) \\
\hline & [ 2.92281$]$ & {$[0.72585]$} & {$[-0.77924]$} & [ 0.69895$]$ & {$[-0.75663]$} & {$[-1.77324]$} \\
\hline \multirow[t]{3}{*}{ MEVDUATDOL.(-4) } & -0.141186 & -0.002755 & -105.5331 & 10.56159 & -0.056831 & 1.993821 \\
\hline & $(0.25139)$ & $(0.26449)$ & (41.6808) & $(5.93701)$ & $(1.10005)$ & $(1.56514)$ \\
\hline & {$[-0.56162]$} & {$[-0.01042]$} & {$[-2.53194]$} & [ 1.77894$]$ & {$[-0.05166]$} & [ 1.27389$]$ \\
\hline \multirow[t]{3}{*}{ ENFLASYON(-1) } & -0.001895 & -0.002618 & -0.860397 & 0.022078 & -0.007324 & 0.004750 \\
\hline & $(0.00121)$ & $(0.00127)$ & $(0.20084)$ & $(0.02861)$ & $(0.00530)$ & $(0.00754)$ \\
\hline & {$[-1.56411]$} & {$[-2.05414]$} & {$[-4.28405]$} & {$[0.77177]$} & {$[-1.38183]$} & [ 0.62983$]$ \\
\hline \multirow[t]{3}{*}{ ENFLASYON(-2) } & -0.001664 & -0.000268 & -0.439760 & -0.001002 & $-3.85 \mathrm{E}-05$ & 0.001594 \\
\hline & $(0.00110)$ & $(0.00115)$ & $(0.18159)$ & $(0.02587)$ & $(0.00479)$ & $(0.00682)$ \\
\hline & {$[-1.51930]$} & {$[-0.23261]$} & {$[-2.42166]$} & {$[-0.03873]$} & {$[-0.00803]$} & [0.23381] \\
\hline \multirow[t]{3}{*}{ ENFLASYON(-3) } & -0.001348 & 0.000644 & -0.304216 & 0.000930 & -0.004694 & -0.000734 \\
\hline & $(0.00100)$ & $(0.00105)$ & $(0.16543)$ & $(0.02356)$ & $(0.00437)$ & $(0.00621)$ \\
\hline & {$[-1.35117]$} & [ 0.61338$]$ & {$[-1.83898]$} & [ 0.03948$]$ & {$[-1.07523]$} & {$[-0.11821]$} \\
\hline \multirow[t]{3}{*}{ ENFLASYON(-4) } & -0.000603 & $6.41 \mathrm{E}-05$ & -0.157445 & 0.015229 & -0.006324 & -0.000834 \\
\hline & $(0.00080)$ & $(0.00084)$ & $(0.13239)$ & $(0.01886)$ & $(0.00349)$ & $(0.00497)$ \\
\hline & {$[-0.75467]$} & {$[0.07628]$} & {$[-1.18926]$} & {$[0.80760]$} & {$[-1.80985]$} & {$[-0.16768]$} \\
\hline \multirow[t]{3}{*}{ FAIZ DEGISIMI(-1) } & -0.001790 & -0.016520 & 1.148662 & 0.183226 & 0.024093 & -0.013435 \\
\hline & $(0.00879)$ & $(0.00925)$ & $(1.45735)$ & $(0.20758)$ & $(0.03846)$ & $(0.05472)$ \\
\hline & {$[-0.20360]$} & {$[-1.78640]$} & [ 0.78819$]$ & {$[0.88265]$} & {$[0.62641]$} & {$[-0.24551]$} \\
\hline \multirow[t]{3}{*}{ FAIZ DEGISIMI(-2) } & 0.034312 & 0.036600 & 7.794388 & -0.363815 & 0.147205 & -0.040179 \\
\hline & $(0.00923)$ & $(0.00971)$ & $(1.52971)$ & $(0.21789)$ & $(0.04037)$ & $(0.05744)$ \\
\hline & [3.71902] & [ 3.77049$]$ & [ 5.09533] & {$[-1.66970]$} & [3.64617] & [-0.69948] \\
\hline \multirow[t]{3}{*}{ FAIZ DEGISIMI(-3) } & 0.030647 & 0.024985 & -2.045228 & -0.271011 & 0.027808 & 0.008716 \\
\hline & $(0.01416)$ & $(0.01490)$ & $(2.34804)$ & $(0.33446)$ & $(0.06197)$ & $(0.08817)$ \\
\hline & [ 2.16405] & [ 1.67685$]$ & {$[-0.87104]$} & {$[-0.81031]$} & {$[0.44873]$} & [0.09886] \\
\hline \multirow[t]{3}{*}{ FAIZ DEGISIMI(-4) } & -0.013463 & -0.035475 & 3.654913 & 0.090207 & 0.049948 & 0.024864 \\
\hline & $(0.01786)$ & $(0.01879)$ & $(2.96084)$ & $(0.42174)$ & $(0.07814)$ & $(0.11118)$ \\
\hline & {$[-0.75389]$} & {$[-1.88813]$} & [ 1.23442$]$ & [ 0.21389$]$ & [0.63918] & [0.22363] \\
\hline \multirow[t]{3}{*}{ KUR DEGISIMI(-1) } & -0.054550 & 0.042965 & -0.460990 & 1.753408 & 0.423560 & -0.015418 \\
\hline & $(0.05935)$ & $(0.06244)$ & $(9.84056)$ & (1.40169) & $(0.25971)$ & $(0.36952)$ \\
\hline & {$[-0.91911]$} & {$[0.68805]$} & {$[-0.04685]$} & [ 1.25092$]$ & [ 1.63087$]$ & {$[-0.04173]$} \\
\hline \multirow[t]{2}{*}{ KUR DEGISIMI(-2) } & 0.211165 & 0.165288 & 16.25868 & 0.657736 & 0.272767 & 0.235439 \\
\hline & $(0.06872)$ & $(0.07230)$ & (11.3938) & (1.62294) & $(0.30071)$ & $(0.42785)$ \\
\hline
\end{tabular}




\begin{tabular}{|c|c|c|c|c|c|c|}
\hline & {$[3.07286]$} & {$[2.28613]$} & [1.42697] & {$[0.40527]$} & {$[0.90708]$} & {$[0.55029]$} \\
\hline \multirow[t]{3}{*}{ KURDEGISIMI(-3) } & -0.008206 & 0.038030 & -1.832249 & 0.163063 & 0.255736 & 0.741337 \\
\hline & $(0.06585)$ & $(0.06929)$ & $(10.9188)$ & $(1.55527)$ & $(0.28817)$ & $(0.41001)$ \\
\hline & {$[-0.12461]$} & [ 0.54888$]$ & {$[-0.16781]$} & {$[0.10485]$} & {$[0.88745]$} & [ 1.80811$]$ \\
\hline \multirow[t]{3}{*}{ KUR DEGISIMI(-4) } & -0.108733 & -0.051350 & 9.198073 & -2.027074 & 0.418413 & 0.276581 \\
\hline & $(0.05725)$ & $(0.06023)$ & $(9.49172)$ & $(1.35200)$ & $(0.25051)$ & $(0.35642)$ \\
\hline & [-1.89935] & {$[-0.85256]$} & [ 0.96906$]$ & {$[-1.49931]$} & [ 1.67026$]$ & [ 0.77600$]$ \\
\hline \multirow[t]{3}{*}{$\begin{array}{l}\text { GSYIH BUYUME- } \\
\text { SI(-1) }\end{array}$} & 0.101231 & 0.023548 & 10.03028 & -0.870553 & 0.164345 & 0.182926 \\
\hline & $(0.03575)$ & $(0.03761)$ & (5.92674) & $(0.84421)$ & $(0.15642)$ & $(0.22255)$ \\
\hline & [ 2.83195] & {$[0.62614]$} & {$[1.69238]$} & {$[-1.03121]$} & {$[1.05067]$} & [ 0.82194] \\
\hline \multirow[t]{3}{*}{$\begin{array}{l}\text { GSYIH BUYUME- } \\
\text { SI(-2) }\end{array}$} & -0.095721 & -0.043065 & -15.47449 & 0.194255 & -0.070777 & 0.150352 \\
\hline & $(0.03505)$ & $(0.03688)$ & (5.81164) & $(0.82781)$ & $(0.15338)$ & $(0.21823)$ \\
\hline & {$[-2.73084]$} & {$[-1.16777]$} & {$[-2.66267]$} & {$[0.23466]$} & {$[-0.46144]$} & [ 0.68896$]$ \\
\hline \multirow[t]{3}{*}{$\begin{array}{l}\text { GSYIH } \\
\text { BUYUMESI(-3) }\end{array}$} & 0.063987 & -0.032561 & -5.998364 & 0.100489 & -0.014057 & 0.256003 \\
\hline & $(0.03558)$ & $(0.03744)$ & (5.89963) & $(0.84034)$ & $(0.15570)$ & $(0.22154)$ \\
\hline & [ 1.79828$]$ & {$[-0.86978]$} & {$[-1.01674]$} & [ 0.11958$]$ & {$[-0.09028]$} & [ 1.15559$]$ \\
\hline \multirow[t]{3}{*}{$\begin{array}{l}\text { GSYIH } \\
\text { BUYUMESI(-4) }\end{array}$} & -0.081860 & -0.102141 & -20.86628 & 1.160903 & -0.294075 & -0.510837 \\
\hline & $(0.04702)$ & $(0.04947)$ & $(7.79613)$ & $(1.11048)$ & $(0.20576)$ & $(0.29275)$ \\
\hline & {$[-1.74093]$} & {$[-2.06467]$} & {$[-2.67649]$} & {$[1.04540]$} & {$[-1.42923]$} & {$[-1.74496]$} \\
\hline \multirow[t]{3}{*}{$\mathrm{C}$} & -0.005085 & 0.002256 & 1.221616 & -0.128096 & -0.033730 & -0.013226 \\
\hline & $(0.00636)$ & $(0.00669)$ & $(1.05460)$ & $(0.15022)$ & $(0.02783)$ & $(0.03960)$ \\
\hline & {$[-0.79939]$} & {$[0.33705]$} & [ 1.15837$]$ & {$[-0.85274]$} & {$[-1.21187]$} & {$[-0.33399]$} \\
\hline $\mathrm{R}^{2}$ & 0.842675 & 0.804982 & 0.875052 & 0.491633 & 0.862119 & 0.665716 \\
\hline Düzeltilmiş $\mathrm{R}^{2}$ & 0.653885 & 0.570960 & 0.725115 & 0.118407 & 0.696662 & 0.264575 \\
\hline
\end{tabular}

Var sisteminde her bir değişken aynı zamanda hem içsel hem de dışsal olduğundan, analiz değişken sayısı kadar farklı regresyon sonucu vermektedir. Düzeltilmiş $\mathrm{R}^{2}$ 'nin temel aldığımız regresyon için 0.65 çıkması modelin açıklama gücünün yüksek olduğunu göstermektedir. Dolayısıyla seçilen değişkenlerin uygunluğu ortaya konmuştur.

Etki tepki analizlerinin amacı, değişkenlerden birine bir birimlik şok uygulandığında diğer değişkenlerin bu değişime gösterdikleri tepkiyi ortaya koymaktır. Grafik 2'de, 10 dönem için etki tepki analizi sonuçları gösterilmiştir. 
Grafik 2. Kredi Dolarizasyonu İçin Etki Tepki Analizi

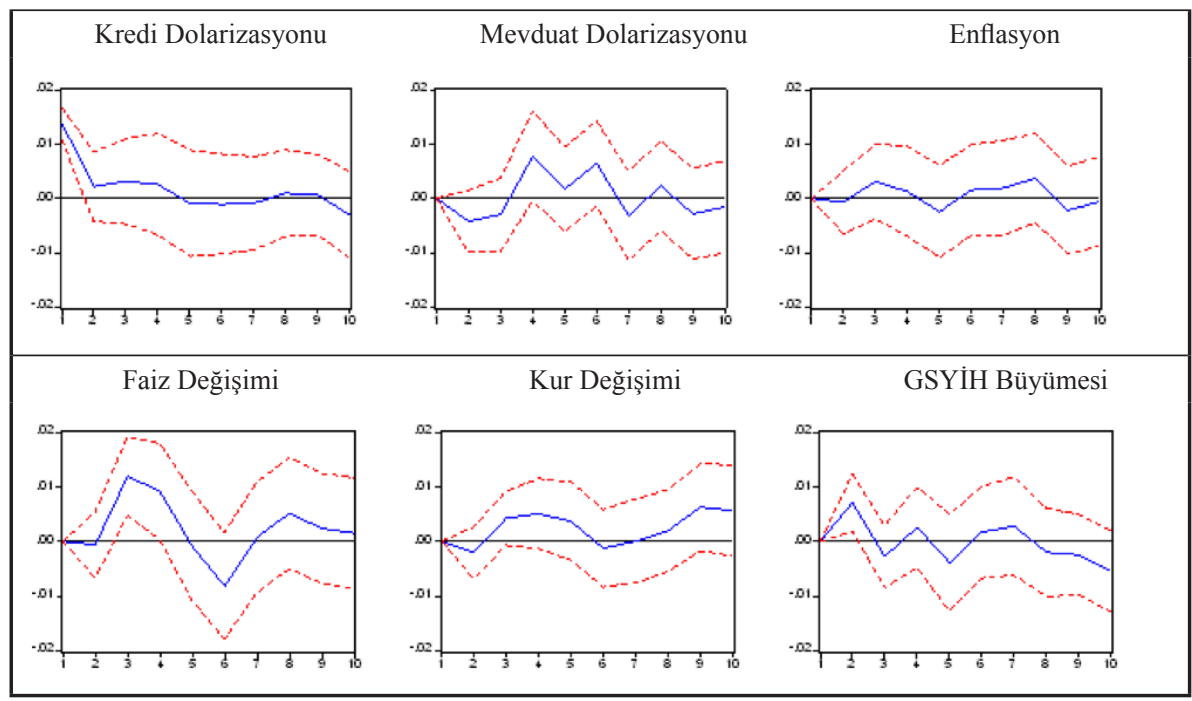

10 periyot için yapılan etki tepki analizi sonuçlarında kredi dolarizasyonun kendisi ve diğer değişkenlerde bir birimlik şok uygulandığında zaman içerisinde vereceği tepkiler gösterilmiştir. Uzun vadede sürecin sıfıra yakınsamadığı, dolayısıyla kredi dolarizasyonunun anılan değişkenlere muhakkak suretle tepki vereceği söylenebilmektedir. Enflasyon değişkeninde volatilite olsa da uzun dönemde sıfira yakınsama gözlenmektedir. Benzer şekilde faiz değişkeninde de sıfıra uzun dönemde yakınsama olsa da volatilite daha yüksek boyuttadır.

Varyans ayrıştırma analizi değişkendeki değişimin ne kadarlık yüzdesinin kendisindeki değişimden ne kadarlık kısmının ise diğer değişkenlerde meydana gelen değişimlerden kaynaklandığını belirtmektedir. Aşağıdaki Tablo 4'te 10 dönem için varyans ayrıştırma analizinin sonuçları verilmiştir.

Tablo 4. Varyans Ayrıştırma Analizi

\begin{tabular}{cccccccc}
\hline DÖNEM & STD.HATA & $\begin{array}{c}\text { KREDI } \\
\text { DOL }\end{array}$ & $\begin{array}{c}\text { MEVD. } \\
\text { DOL. }\end{array}$ & ENF. & FAİZ & KUR & GSYİH \\
\hline 1 & 0.013840 & 100.0000 & 0.000000 & 0.000000 & 0.000000 & 0.000000 & 0.000000 \\
2 & 0.016417 & 72.84018 & 6.505226 & 0.161480 & 0.132388 & 1.516364 & 18.84436 \\
3 & 0.021610 & 44.17418 & 5.618389 & 2.180392 & 30.81868 & 4.736740 & 12.47162 \\
4 & 0.025549 & 32.64076 & 13.36125 & 1.803247 & 34.86662 & 7.372906 & 9.955223 \\
5 & 0.026304 & 30.90403 & 13.04654 & 2.541694 & 33.01812 & 8.913919 & 11.57570 \\
6 & 0.028420 & 26.60715 & 16.32573 & 2.485667 & 36.46758 & 7.826877 & 10.28700 \\
7 & 0.028825 & 25.95565 & 17.09415 & 2.868750 & 35.52559 & 7.608471 & 10.94739 \\
8 & 0.029768 & 24.44105 & 16.64622 & 4.277929 & 36.34008 & 7.577583 & 10.71714 \\
9 & 0.030831 & 22.83457 & 16.34753 & 4.482703 & 34.48017 & 11.23786 & 10.61717 \\
10 & 0.032040 & 22.06771 & 15.37176 & 4.181566 & 32.15638 & 13.47892 & 12.74367 \\
\hline
\end{tabular}


Kredi dolarizasyonunun kendisi üzerindeki etkisinin diğer değişkenlerden farklı olarak dönemler ilerledikçe düştüğü, diğer değişkenlerin özellikle de faiz değişimi ve mevduat dolarizasyonundaki değişimin etkisinin hızlı bir şekilde arttığı Tablo4'ten görülmektedir.

\section{Sonuç}

Dolarizasyon, para politikası araçlarını etkisiz hale getirerek ekonomik istikrarı bozucu etkileri nedeniyle akademik yazında çok tartışılan konulardan biridir. Bankacılık sistemi içerisinde karar alıcıların etki alanında olmayan yabancı bir para biriminden varlık ve yükümlülüklerin bulunması, mevcut riskleri artırıcı bir unsur olmaktadır. Kişi ve kurumları yabancı para birimine yönlendiren, başka bir deyişle dolarizasyonu destekleyen unsurlar ortadan kaldırılmadan serbest bir ekonomide dolarizasyon düzeylerini düşürmek mümkün olamamaktadır. Bu nedenle çalışma, temel makroekonomik değişkenler ile dolarizasyon ilişkilerini sorgulamaya yönelik gerçekleştirilmiştir. Öncelikle dolarizasyonun ekonomiye yüklediği maliyet olarak krizler tartış1mış, tarihsel kriz modelleri ele alınmıştır. Özellikle kovid_19 salgının yarattığı ekonomik tahribat sonrası oluşan finansal kriz ile geçmiş kriz modelleri, benzerlikler ve farklılıkları açısından dikkat çekmektedir. Analiz kısmında da dolarizasyon düzeyi, kredi ve mevduat dolarizasyonu olarak ayrilarak, kredi dolarizasyonunun mevduat dolarizasyonu, faiz değişimi, kur değişimi, enflasyon ve Gayri Safi Yurtiçi Hasıla değişimi ile ilişkisi ortaya konmaya çal1şı1mıştır. Ele alınan tüm değişkenlerin 2001 kriz döneminde yüksek volatilite gösterdiği görülmektedir. Ancak, dolarizasyonun iki boyutu olarak kredi ve mevduat dolarizasyonunda kriz sonrası dönemden 2008 yılına kadar olan dönemde düşüş trendi oluştuğu gözlemlenmiştir. Analiz için kullanılan yöntem olarak vektör otoregresyon modeli seçilmiştir. Bu modelde kredi dolarizasyonu bağımlı değişken alınsa da diğer tüm değişkenleri de ayrı ayrı bağımlı değişken olarak aldığ1, etki tepki ve varyans ayrıştırma analizlerine olanak sağladığı için değiş̧kenler arası ilişkileri araştırmaya en uygun modeldir. Analiz sonuçlarına göre kredi dolarizasyonunu ele alınan değişkenlerin açıklama gücü \% 65 gibi sosyal bilimler için yüksek sayılabilecek bir değerde bulunmuştur. Etki-tepki analizi 10 dönem için uygulanmıştır. Bu analizine göre; her bir dönem üç aylık periyotlardan oluştuğu için 30 aylık uzun dönemde de değişkenlerin etkisinin devam ettiği ve azalma olmadığı görülmüştür. 


\section{Kaynakça}

Arteta, C., Ó. (2003). Are Financially Dollarized Countries More Prone to Costly Crises?, Federal Reserve System International Finance Discussion Papers , 763, 1-51.

Bleaney, M., Bougheas, S. \& Skamnelos, I. (2008). A Model of the Interactions Between Banking Crises and Currency Crises, Journal of International Money and Finance, 27, 695706.

Burnside, C., Eichenbaum, M. \& Rebello, S. (2001). Hedging and Financial Fragility in Fixed Exchange Rate Regimes, European Economic Review, 45(7), 1151-1153.

Feldstein, M. (2002). Economic and Financial Crisis in Emerging Market Economies: Overview of Prevention and Management, NBER Working Paper Series, 1-12, Erişim Adresi: https://www.nber.org/system/files/working_papers/w8837/w8837.pdf .

Flood, R. P. \& Garber, P. M. (1989). The Linkage Between Speculative Attack and Target Zone Models of Exchange Rates. NBER Working Paper Series, No: 2918,1-23, Erişim Adresi: https://ideas.repec.org/p/nbr/nberwo/2918.html .

Henderson, D., \& Salant, S. (1978). Market Anticipations of Government Policies and the Price of Gold, Journal of Political Economy, 86, 627-648.

International Monetary Fund World Economic Outlook. (1998). Financial Crisis: Characteristics and Indicators of Vulnerability, 1-130, Erişim Adresi: www.imf.org/external/pubs/ ft/ weo/weo0598/index.htm .

Kennedy, P. (2006). Ekonometri Kılavuzu, Gazi Kitabevi, Ankara

Krugman, P. (1997). Currencies and Crisis, MIT Press, London

Rosier, B. (1994). İktisadi Kriz Kuramları. İstanbul: İletişim Yayınları

Obstfeld, M. (1984). Balance of Payment Crisis and Devaluation, Journal of Money, Credit and Banking, 16(2), 263-283.

Y1lmazkuday, H. (2008). Twin Crises in Turkey: A Comparison of Currency Crisis Models , The European Journal of Comparative Economics, 5(1), 107-124. 
